\title{
Adolescents With Autism Spectrum Disorder and Anorexia Nervosa Comorbidity: Common Features and Treatment Possibilities With Cognitive Remediation Therapy and Oxytocin
}

\author{
Barbara Plemeniti Tololeski ${ }^{1}$, Ana Suhodolčan Grabner ${ }^{2}$ and \\ Hojka Gregoric Kumperscak ${ }^{3,4 *}$
}

${ }^{1}$ Centre for Mental Health, Unit for Adolescent Psychiatry, University Psychiatric Hospital Ljubljana, Ljubljana, Slovenia, ${ }^{2}$ General Hospital Slovenj Gradec, Slovenj Gradec, Slovenia, ${ }^{3}$ Department for Child and Adolescent Psychiatry, University Medical Centre, Maribor, Slovenia, ${ }^{4}$ Faculty for Medicine, University of Maribor, Maribor, Slovenia

OPEN ACCESS

Edited by:

Marija Raleva,

Saints Cyril and Methodius University

of Skopje, North Macedonia

Reviewed by:

Filippo Muratori,

Fondazione Stella Maris (IRCCS), Italy

Milica Pejovic-Milovancevic,

Institute of Mental Health, Serbia

*Correspondence:

Hojka Gregoric Kumperscak

hojka.gregoric@guest.arnes.si

Specialty section:

This article was submitted to Child and Adolescent Psychiatry, a section of the journal

Frontiers in Psychiatry

Received: 26 March 2021

Accepted: 01 July 2021

Published: 03 August 2021

Citation:

Plemeniti Tololeski B, Suhodolčan Grabner $A$ and Kumperscak HG (2021) Adolescents With Autism Spectrum Disorder and Anorexia

Nervosa Comorbidity: Common Features and Treatment Possibilities With Cognitive Remediation Therapy and Oxytocin

Front. Psychiatry 12:686030 doi: 10.3389/fpsyt.2021.686030
Autistic traits or autism spectrum disorder (ASD) can be found in 4\% to 52\% of anorexic patients, which makes the treatment of these patients very challenging. In this review, possible ways to treat ASD and anorexia nervosa (AN) comorbidity in children and adolescents are summarized. Over recent years, the focus has shifted from searching for the evidence of connections between these two disorders, which have started with Gillberg's study in 1983, to searching for more effective and holistic treatment of this comorbidity. The latter is known to contribute to more severe courses and worse prognosis, which is probably related to the obstacles in both diagnosing and treating. Since AN usually starts in early adolescence and high-functioning ASD children seem to begin struggling with increased pressure in adolescence, while various comorbidities can occur, it is important to improve the treatment of this comorbidity in young patients and to tailor it specifically in terms of diagnosing. In this paper, a literature review is conducted on common features and promising treatment possibilities. We describe cognitive remediation therapy and the promising pharmacotherapeutic candidate oxytocin with a special focus on adolescents.

Keywords: autism spectrum disorder, anorexia nervosa, comorbidity, adolescents, cognitive remediation therapy, oxytocin

\section{INTRODUCTION}

Anorexia nervosa (AN) is a serious eating disorder, which is more often found in women and usually starts in adolescence. A study of a 30-year outcome of adolescent-onset AN has recently found that one-fifth of patients has had a chronic eating disorder (1). Many of these girls and young women seem to have problems in social functioning and have neurocognitive-specific features, which resemble the difficulties seen in autism spectrum disorder (ASD) patients. In 1983, Gillberg has been the first to find a high prevalence of autism in adult anorexic patients (2). Since then, many researchers have confirmed his results, finding autistic traits or ASD in $4-52 \%$ of anorexic 
patients according to the most recent review (3). What was once described as high-functioning autism (HFA) or Asperger syndrome (AS) seems to be harder to diagnose in women. The term HFA is an unofficial term used for people who would likely have been diagnosed with AS in the past. AS was removed from the Diagnostic and Statistical Manual of Mental Disorders in 2013 (4). Since then, the severity of ASD is indicated by a level from 1 to 3. According to DSM-5, people with HFA or AS would be diagnosed as ASD with a severity level 1, meaning that they can speak, read, write, and handle basic life skills and live independently. However, they still have difficulties in social interactions, conversations, including inflexibility of behavior and interest, and difficulty switching between activities, and are facing problems of organization and planning. In this paper, we continue to use the term ASD to cover the terms autism, HFA, and AS.

There are diagnostic difficulties in diagnosing AN in women with ASD. Due to the known camouflaging (5), diagnostic overshadowing (6), and partly also because of biases in assessment (7), many girls still pass by undiagnosed or misdiagnosed in childhood. Camouflaging is a process through which individuals mask autistic traits and is more common in girls and women than men (5). Diagnostic overshadowing explains a delay in diagnosing ASD in women with ASD symptoms being "overshadowed" by symptoms of comorbid disorder, such as eating disorder, depression, or anxiety (6). Often, it is only the comorbid disorder that refers a girl with ASD to the psychologist or psychiatrist for the first time. AN can be one of those, especially in early adolescence, when adolescents with ASD face normal developmental tasks, such as the adjustment to rapid and profound physical changes, development of stable and productive peer relationships, learning to manage their sexuality, and the need to develop expanded verbal skills to accommodate more complex concepts, which are even more challenging for them in comparison to neurotypical adolescents. Clinical practices have shown poorer outcomes for patients with this comorbidity (8), more severe clinical presentation on admission to inpatient care (9), and thus a need to introduce modified treatment of this comorbidity in young patients.

Recent data analysis on cognitive hallmarks in AN and ASD proposes common features, besides sensory sensitivities (10) and poor social functioning $(11,12)$, that contribute to the similarities in thinking in regard of these two disorders. There are indications that problems in cognitive flexibility and central coherence constitute the core for these cognitive features (13-16).

One target of research concerning the cognitive aspect in individuals with ASD and AN over the last years is cognitive remediation therapy $(\mathrm{CRT})(17,18)$. The assumption is that improving the cognitive function of the individual might enhance the ability to manage daily life tasks. The goal is to develop metacognition, i.e., teaching individuals to think about the way they think and focusing more on the process instead of the results $(19,20)$.

The other interesting target of recent research concerns the poor social functioning of young patients with this comorbidity. In the field of psychopharmacologic treatment, where there is still an absence of a specific drug for treating either AN or ASD, the use of oxytocin can be seen as a promising agent for augmentation, since it is known for its prosocial effects, from which these patients could benefit a lot.

Since treating this comorbidity poses quite a challenge and there are currently no clear guidelines, the South London and Maudsley NHS Trust Eating Disorders Services developed a new pathway, which was introduced in January 2018 to better assess the problems of ASD patients with an eating disorder. The Pathway for Eating disorders and Autism developed from Clinical Experience (PEACE pathway) provides a more customized approach toward treating the comorbidity of ASD and eating disorders (21), considering that this population of patients present with a more prominent clinical presentation and tend to have more trouble adhering to traditional treatment programs. As a result, outcomes are poorer and hospital admissions are longer $(8,9)$.

They may experience some additional issues when compared to neurotypical peers, such as communication difficulties, which may lead to more trouble engaging to treatment, sensory problems that subsequently motivate food restriction, and higher levels of cognitive rigidity, which makes it hard to modify maladaptive behaviors and cognitions $(22,23)$.

Several adaptations and improvements to the traditional approaches were made implementing the PEACE pathway, such as additional education of healthcare professionals in their multidisciplinary teams leading to better tailoring of the treatment to the individual and more flexibility in their approach. Using questionnaires, like The AQ10 (Autism Quotient-10) (24), applying the updated algorithm to score the ADOS-2 (25), as it has been found to have increased sensitivity for females with AN (26), and using a sensory sensitivity scale that was given to all patients at the start of their treatment lead to better identification of possible autistic features in admitted patients (21). The patients were engaged in psychoeducation and experiential exercise-based cognitive and emotional training programs, using CRT and Cognitive Remediation and Social Skills Training (CREST) in individual and group formats immediately after admission, regardless of BMI. Therapeutic exercises were revised and adapted into a more concrete and tangible form (21). Observations showed that the patients presented with significant change in self-report and neuropsychological outcome after individual CRT and CREST. After group sessions, there were less significant changes in self report (27-29), although patients with high ASD traits experienced the groups as a safe, nonthreatening environment, which might provide a good base for future tolerance of social situations (21).

In regard of addressing sensory sensitivities, the ward was tailored to the sensory needs of the patients and a specialized menu was co-produced by dieticians and patients. Clinicians received psychoeducation and support, which was also provided to the carers of their patients (21). A direct consequence of these adaptations was a clear reduction in the average duration of admission, average costs of admissions were lower, patients and carers gave positive feedback, while the confidence of the clinical team regarding treating patients with comorbid ASD and AN has increased (30). 
There is evidence that CRT increases set-shifting abilities in individuals with AN and ASD features (27) and it presents a promising therapeutic approach. Nevertheless, there is still a gap regarding standardized treatment guidelines. Similarly, the poor functioning is one of the core symptoms in this comorbidity that seems to be important for etiopathogenesis, severity of disease, and prognosis. Oxytocin, which seemed to be of low levels in both anorexia and ASD according to some studies, is understood as an important promising candidate for augmentation treatment due to its involvement in social behavior and rewarding system in the central nervous system.

Treatment of ASD and AN comorbidity is very challenging and the data including children and adolescents are sparse. In this review article, we gathered information from most recent reviews and articles on the cognitive remediation techniques and oxytocin applied in individuals with AN and ASD traits and summarized findings from studies predominantly conducted over the last 6 years.

With reference to available data, both approaches, whether pharmacological or psychotherapeutic, seem to present a promising treatment option for this specific population of patients. Particularly regarding adolescents, the literature on this subject seems deficient; there are a limited number of studies that depict the implementation of oxytocin treatment or cognitive remediation techniques being used, but precisely the accessible literature presents a field worth of further exploration.

\section{COGNITIVE REMEDIATION THERAPY}

CRT was first implemented for patients suffering from problems caused by brain lesions (31); however, over the years, it has been increasingly used as an intervention for various psychiatric illnesses (32-38). It targets cognitive domains such as attention, memory, visual and spatial functions, abstract and holistic thinking, and executive functions such as planning, cognitive flexibility, and problem solving in a way that it allows patients to embrace their weaknesses and strengths and reframe their thinking styles $(27,39)$.

Central coherence refers to the cognitive capacity to integrate information into a more global meaning with the assumption that executive functions and social cognition abilities are preserved (40). Weak central coherence presents itself as the preoccupation with details at the cost of global/contextual processing (17). Setshifting abilities comprise the ability to flexibly switch through numerous mental tasks, change mindset, and, consequently, adapt more rapidly and respond to new situations or events (41). These abilities are of utter importance for cognitive and subsequently behavioral flexibility in everyday life. Weaknesses in set-shifting result in cognitive rigidity, and since it has been established that there are similarities in cognitive and behavior profiles in patients suffering from ASD or AN (10, 13, 16, 27, 42-45), the implementation of CRT techniques in patients with comorbid ASD and AN poses a valuable possibility of amelioration of these aberrations.

As mentioned before, there is a high comorbidity rate between ASD and AN, and over the last years, there have been several studies that support the usefulness of CRT techniques in AN and even some that see benefits for patients with ASD (17, 46-48).

\section{Cognitive Remediation in ASD}

To date, there have been some randomized control trials regarding CRT interventions in ASD patients (49-52) as well as some relevant non-randomized control studies (53, $54)$, case series $(27,55-57)$, feasibility studies (58), and case studies (59) of which some also included children and adolescents $(49-51,55,57)$.

It has been found that this particular form of therapy can be beneficial in improving cognitive flexibility, social cognition, and the heterogeneity of executive function, even clinical symptoms and working memory in autistic children as one study, including children and adolescent (age 6-21), established (55). On the other side, due to some methodological limitations of the studies conducted, it poses a question of generalizability of the submitted results (18).

Since individuals with ASD have trouble generalizing learned skills into real-life situations $(56,60)$, it might be worth considering modifying the standardized CRT interventions, such as setting more concrete examples, dismissing open ended questions, and implementing modeling, which may be helpful for learning, maximizing effectiveness, and reducing dropout rates. Perhaps a combination of CRT with social skills training might appear useful in solving difficulties in daily life (48).

On another important note, the trend of computer-based interventions is on the rise $(53,54)$; however, the research evidence regarding this is lacking and the interpretation of such results should be used with caution, particularly because it is difficult to translate these learned strategies into real-life situations (18).

\section{Cognitive Remediation in AN}

Regarding the application of CRT interventions in populations of patients suffering from AN, there have been some naturalistic studies (46) conducted in the last years, as well as randomized control trials $(47,61-64)$, case series (65-78), and single case reports (79-81) mostly including adult populations alongside adolescents $(47,61,63,64,77)$ or purely based on adults $(46$, $62,73,78-81)$, but also some being carried out on adolescents $(67,68,70,72,75)$.

Through different cognitive exercises, metacognitive strategies, awareness, and their implementation in real-life situations, the aim of CRT in individuals suffering from AN is to improve the rigid and inadequate processing styles $(67,82)$. Despite several methodological challenges, the results appear to favor individual CRT, in that it was associated with lower dropout rates than group CRT and has the potential of creating a positive patient/therapist alliance. On the other hand, some positive aspect was also given to group CRT and family CRT but one should remain cautious because of the possibility of negative reinforcement in group dynamics as well as the fact that family CRT should not remain the only applied form of therapy. Instead, it should rather be used as an adjunct to other therapeutic procedures (17). 
Some of the more recent research has validated similar cognitive processing styles in adolescents compared to adults $(45,83,84)$, which would in turn pose a feasible ground for application of CRT techniques in the adolescent population.

Over the last years, applying CRT in younger adolescent patients with $\mathrm{AN}$ has shown improvements in central coherence and somewhat less consistently in set-shifting $(66,75,85-$ 87). There were even significant improvements in executive functioning observed $(67,75,85,86)$. Often, patients and therapists gave positive feedback $(66,69,86,88,89)$ and low dropout rates were described $(69,86)$. Considering group CRT in adolescents with severe and complex eating disorders, there are some data about higher dropout rates; however, patients were generally satisfied with this kind of treatment approach $(73,86)$.

Nevertheless, it is worth acknowledging that improvements in set-shifting and central coherence following group CRT were more consistently documented in adult populations than in adolescents $(14,90,91)$ as one recent systematic review established (10). The root of this issue seems to be the lack of research regarding adolescents, compared to the number of research done in adult populations (10). Despite the fact that most RCTs to this point were conducted on adult populations with $\mathrm{AN}$, there is an indication for positive outcome following individual (66, 75), group (73), and family-based CRT in adolescents suffering from $\mathrm{AN}(70,71)$.

Another reasonable subject to consider is using CRT as an adjunct or pre-treatment option for more extensive psychotherapeutic work in cases of acute $\operatorname{AN}(79,80,92)$ and as an enhancement of the current therapeutic measures for patients with an enduring eating disorder (61).

There are studies that show that using CRT in addition to medical stabilization for adolescent inpatients with AN could aid greater patient motivation to change and thus reduce hospital admission duration. It also enhances the cognitive skills needed for more extensive psychotherapy, and there have been positive changes noted in neurocognitive functioning following CRT in combination with other psychotherapeutic approaches $(39,86)$. Studies to further investigate the feasibility of CRT interventions in this domain are currently taking place $(20,93)$.

\section{Cognitive Remediation in ASD and AN}

There has been little research on the clinical effects of CRT in patients with comorbid ASD and AN and basically no relevant data on CRT implementation in adolescents who suffer from both ASD and AN $(27,48,56,59)$. Even in the present studies, some of the participants with AN did not have a valid ASD diagnosis and were only assessed using screening tools and self-report questionnaires (18).

By taking a closer look into the results of these studies, there were some contradictory findings in the central coherence improvement as two studies reported positive changes $(48,59)$, one study found no statistically significant improvements in central coherence (18), and in one of the studies, there were no significant changes in self-reported thinking styles after group CRT or improvements in motivation in the group of patients with high ASD traits, although patients gave positive feedback on the applied techniques (56).
After a trial of individual CRT, patients self-reported positive changes in cognitive flexibility and an improvement in mean scores for cognitive flexibility was found; however, there were no significant changes found in using the performance-based measure for cognitive rigidity (the Brixton Test) (18).

In the only case study discussing the clinical implementation of CRT for AN in ASD in a 21-year-old female patient (59), there were also some improvements noted in cognitive flexibility, alongside with an increase in body mass index (BMI).

Regarding the form of CRT delivered for this comorbidity, group treatment showed less improvements following therapy, which may be due to the possibility that patients with high ASD features need some adjustment to the standard type of cognitive training delivery and all in all a modified individual approach of CRT would eventually be more suitable (56).

Considering the neurocognitive similarities in individuals with ASD and AN, discussed in this article, CRT certainly seems like a promising technique to incorporate into existing treatment approaches of these patients. The prosperity of group CRT for comorbid adolescents should warrant additional investigation, precisely because of the unique thinking patterns, emotional processing, and behavioral features of this patient population. It would also be important to explore the long-term effects of CRT in adolescents with ASD and AN by applying measurements for facing everyday challenges or quality of life.

Data on implementing CRT in patients with comorbid ASD and AN, particularly younger populations, remains scarce, and although it gives rise to some positive outcomes, further research is needed $(19,48,56,59)$.

\section{OXYTOCIN}

\section{Why Oxytocin?}

Oxytocin is a natural hormone and neurotransmitter with a broad spectrum of functions in animals and humans, being known colloquially as the "love hormone." Though many other pharmacotherapeutic agents have an important role in the treatment of both AN and ASD and their comorbidities, oxytocin has drawn the attention of researchers as promising medicine in psychiatry and somatic medicine years ago.

In regard to the absence of an approved medication for $\mathrm{AN}$ or ASD, it is one of the novel possible agents studied in these two diseases as well, especially due to the recognized impaired emotional-social processing in ASD and AN patients. One of its probably most important effects in mammals, apart from being involved in sexuality, labor, and lactation, is the induction of prosocial behavior. As such, it can induce bonding (94) and enhanced empathy (95). It also shows anxiolytic properties in humans (96) and antidepressant-like effects in animals (97), which can be beneficial in ASD, since depressive and anxious disorder is commonly comorbid. It is also important in stress, showing protective effects (98) with lowering concentrations of cortisol (99). The study from 2018 (100) showed that the density of oxytocin receptors in ventral pallidum, an area in the mesolimbic reward pathway, decreases with age. They also found the peak of oxytocin receptor density in that area in early 
childhood in neurotypical children, which suggests that early childhood is a critical period for social development in humans.

Oxytocin also has a special role in feeding with its anorexigenic effects, which were also proven in experimental setting in animals, where a single dose of oxytocin reduced the feeding, but did not have an effect on food intake in humans (101).

In the last decade, there has been an increasing amount of literature devoted to testing its positive effects through intranasal administration in patients with different psychopathology. Below, we review studies on the use in AN and ASD with special emphasis on studies examining adolescents, which are unfortunately still scarce; therefore, it is difficult to draw definite conclusions.

\section{Oxytocin in AN}

$\mathrm{AN}$ is one of the most difficult mental disorders to treat, especially in children and adolescents where, due to its egosyntonic nature in early age, there is no or poor insight. Regarding the absence of FDA-approved medication, our pharmacotherapeutic attempts to help patients with AN symptoms and its comorbidities include the use of SSRI, atypical antipsychotics, such as olanzapine and benzodiazepines, frequently in combination. In his recent review, Frank (102) suggests future studies of combinations of more medications used together, combinations of medications and psychotherapy, and some novel agents, especially those targeting dopamine system in conjunction with medications to modulate GABA neurotransmission.

The beforementioned anorexigenic effects of oxytocin seem to exclude it from the list of possible agents for treating AN. However, according to recent findings, oxytocin is probably involved in etiopathogenesis of AN. Tyszkiewicz-Nwafor et al. (103) conducted a study on adolescents with AN and found elevated oxytocin concentrations that insisted even after partly weight restitution. Their findings are contradictory to a series of studies that found lower oxytocin concentrations in patients with AN (104). A correlation between peripheral levels and central activity is still questionable (104).

Interestingly, lower oxytocin levels are supposed to be associated with increased severity of social-emotional functioning impairment and greater severity of alexithymia in AN (105), which could be the consequence of lower insula activity due to lower oxytocin levels (106). The pathology of insula has been proven to be connected to alexithymia (107). According to a study from 2020, alexithymia is thought to be important in pathogenesis and treatment of eating disorders in autistic and neurotypical individuals (108).

Although studies from the previous decade showed promising effects of intranasal oxytocin in anorexic patients, e.g., with attenuated attentional bias for fat stimuli and increased emotion recognition (109), recent systematic review and meta-analysis (110) warn of potential shortcomings of those studies. Oxytocin also had no effect on the amount of drink intake in two studies $(111,112)$. However, lowered cortisol concentrations after meal and oxytocin administration was found in both serum (112) and saliva (113), which potentially could help to ease the anxiety linked to meals in anorexic patients.
However, oxytocin receptor polymorphism seems to be important too. It was found to be related to the severity of eating disorders with alleles for two SNPs (rs53576 and rs22542988) identified as being responsible for a more severe course of anorexia (114). The study from 2018 (115) showed that OXTR SNP rs2254298 could be involved in modified neural response on social stimulus in AN.

As seen, the results of the studies done mainly on adult population are unambiguous, starting with differences in oxytocin levels in AN from low to increased. The concentrations of oxytocin in the central nervous system after intranasal administration may also not be sufficient (110). More studies on adolescents are required in the future due to the possible effect of disease duration and adaptation mechanisms in adult patients and to provide more answers to the state/trait question regarding altered oxytocin in AN.

\section{Oxytocin in ASD}

Oxytocin is seen as a promising psychopharmacological candidate for augmenting ASD regarding its prosocial effects and the role in emotional-social processing. Moreover, it may be even more significant in childhood and adolescence due to an age dependence of oxytocinergic system (100). In the study (100) of post-mortem brain tissue of individuals with ASD and neurotypical individuals, they found that individuals with ASD lacked a peak of density of oxytocin receptors in ventral pallidum in early childhood, which might explain a deficit in social functioning in autism due to impaired connections between prosocial behavior and reward system. Early childhood seems to be a critical period with oxytocinergic system involved in the etiology of ASD. The study in mice showed that oxytocin administration in a critical development phase prevented social deficits later in life of mice with a mutated gene that was also found in patients with ASD (116). Nevertheless, the results of research are still quite contradictory, from low oxytocin levels found in children with ASD (117) to the varying ones (118). The complexity of oxytocinergic system can be imagined through findings such as increased levels of inactive form of oxytocin found in children with ASD (119), large heritability of oxytocin levels (114), oxytocin receptor gene polymorphism being related to the symptom severity in ASD (114), and the importance of oxytocin receptor gene methylation as epigenetic regulation. The latter was shown to be linked to a decrease in the extent to which social information captures attention, which could be important in ASD etiology (120). A recent study (121) found that extreme values of DNA methylation in the first intron of oxytocin receptor gene correlate with a lower IQ and more social problems in individuals with ASD and ADHD.

After intranasal administration of oxytocin in adolescents with autism, they found improved emotion recognition (122); however, when administered twice daily for 8 weeks, no improvements were observed in social behavior in adolescents with ASD (123). On the other side, some of the studies found improved social communication in children and adolescents with ASD after longer periods of oxytocin administration (124, 125). In recent years, they also measured changes in brain with fMRI after administration of oxytocin in studies, some of them 
conducted on the adolescent population (126-128), which could be more objective in comparison to the ones measuring oxytocin effects by behavioral findings [reviewed in (129)].

In summary, oxytocin seemed to enhance the processing of social information and facilitate reward responses in autistic individuals. In this recent review from 2020 (129), authors suggest that future research should try to maximize the effects of oxytocin by creating more personalized dosing schedules, considering initial basal levels of endogenous oxytocin in individuals as well as factors such as sex, comorbid disorders, and others. Furthermore, future research should investigate the combination of oxytocin administration and behavioral intervention, since social stimuli can be more rewarding for individuals with ASD after oxytocin administration resulting in a more efficient behavioral intervention (129).

\section{Oxytocin in AN and ASD Comorbidity?}

Treating children and adolescents with AN and ASD comorbidity by applying intranasal oxytocin is still not possible according to the latest research on oxytocin administration in both conditions as seen above. However, this field should be further investigated in the future to keep oxytocin as a promising candidate for augmentation in treatment. Improvement of social impairments in this group of patients could mean a lesser extent of AN chronification. As suggested by Baker (129), future studies should investigate the efficiency of combination of oxytocin administration and behavioral interventions in ASD patients. In the light of a modern concept of precision psychiatry, the individuals with lowered oxytocin levels should be detected to benefit the most. More studies on oxytocin administration in this population burdened with AN and ASD should be conducted in the future.

Alexithymia could be a new focus in future research. It occurs in half of the autistic individuals and is greatly connected with their social functioning. It is understood as at least partly responsible for a greater risk for any eating disorder (108). With the knowledge that lower oxytocin levels are linked with decreased activity in insula (106), thus causing more alexithymia, we can hypothesize that further studies should keep oxytocin as a candidate in the treatment for this comorbidity. Childhood and adolescence seem to be the most sensitive time for the development and maturing of the oxytocin system, as well as for the social inputs from the environment. Therefore, combining oxytocin administration and behavioral interventions could result in less impairment in social functioning in adult age and life-quality improvement. Of course, further studies on youth are required in the future, including genetics, neuroimaging, and combined pharmacological and behavioral techniques, as proposed by Baker (129) for ASD.

\section{DISCUSSION}

Treating young patients with ASD-AN comorbidity has been improving in recent years due to better and earlier recognition of ASD, especially in girls as well as the progress in the development of interdisciplinary programs for youth with ASD. The examination of recent literature shows that among other interventions and therapies, young patients with AN and ASD could also benefit from CRT and oxytocin application.

An advantage of CRT is its flexible and modifiable approach, not only regarding the form of delivery, meaning application in an individual, family, or group scheme, but also interventionwise to best fit the individual in treatment (20). Future implementation should aim toward a modification of CRT techniques, making them more adapt to the deviations in social functioning in patients with ASD.

The use of oxytocin, on the other hand, still needs to be proven in more studies in this group of patients. According to the studies already done, we can conclude that oxytocin should stay a possible psychopharmacologic candidate, which could help to prevent chronification of AN, due to its promising ability to improve their poor social functioning. Future studies should combine oxytocin administration together with behavioral interventions, as proposed by Baker (129) for ASD patients, which could be even more true for patients with AN and ASD comorbidity.

Applying CRT therapy and treating comorbid patients with oxytocin presents a favorable new ground for treatment and research, also because there were no reports on the important side effects of intranasal administration of oxytocin (130) or CRT. Still, there are some limitations to consider. Using stricter patient inclusion criteria and using standardized and up-to-date diagnostic questionnaires for ASD when selecting the research groups of potential patient candidates would contribute to more relevant end results.

This review shows that studies on treatment of ASDAN comorbidity are still sparse, especially on adolescents. Studies on CRT and oxytocin in adolescents are very rare, so drawing ultimate conclusions of its usefulness might still be premature. Future studies should focus on young patients with this comorbidity, combining psychotherapy and pharmacotherapy. The approach of precision medicine should be undertaken due to known individual differences on autism spectrum, gender differences, and many comorbidities in ASD children and adolescents. It would be necessary to include larger treatment centers into conducting more studies with a larger patient sample. Particularly, more RCTs featuring adolescents are needed to assess the effectiveness of CRT and use of oxytocin in this age group. By doing so, this may possibly lead to earlier discovery of comorbid features, a more suitable and thorough therapeutic approach leading to less recurrent hospital admissions, a lower dropout rate, and fewer psychiatric comorbidities.

Until more studies are done, we suggest to follow the South London and Maudsley NHS Trust Eating Disorders Services first guidelines regarding the treatment of comorbid patients with ASD and AN. The PEACE pathway $(21,30)$ was published with comprehensive adaptations to treatment and set a promising foundation for future therapeutic work. In view of the positive outcomes, this approach could also be used as a base for the potential implementation in children and adolescents with 
comorbid ASD and AN. Further investigation is warranted, with future studies featuring the PEACE pathway guidelines, thus gathering more data of the benefits that it might provide.

\section{AUTHOR CONTRIBUTIONS}

BP and AS: study design, collection and assembly of data, data interpretation, and contributed to the manuscript equally. HK: study design, article review, revision, and final approval of the

\section{REFERENCES}

1. Dobrescu S, Dinkler L, Gillberg C, Råstam M, Gillberg C, Wentz E. Anorexia nervosa: 30-year outcome. Br J Psychiatry. (2020) 216:97104. doi: 10.1192/bjp.2019.113

2. Gillberg C. Are autism and anorexia nervosa related? Br J Psychiatry. (1983) 142:428. doi: 10.1192/bjp.142.4.428b

3. Westwood H, Tchanturia K. Autism spectrum disorder in anorexia nervosa: an updated literature review. Curr Psychiatry Rep. (2017) 19:41. doi: 10.1007/s11920-017-0791-9

4. American Psychiatric Association. Diagnostic and Statistical Manual of Mental Disorders 5th ed. Arlington: American Psychiatric Association (2013). doi: 10.1176/appi.books.9780890425596

5. Jorgenson C, Lewis T, Rose C, Kanne S. Social camouflaging in autistic and neurotypical adolescents: a pilot study of differences by sex and diagnosis. $J$ Autism Dev Disord. (2020) 50:4344-55. doi: 10.1007/s10803-020-04491-7

6. Brown M, Fuller-Tyszkiewicz M, Krug I, Stokes MA. Diagnostic overshadowing in autistic women. In: Poster Presented at: INSAR 2019 Annual Meeting. Montreal, QC (2019).

7. Blair BJ, Blanco S, Ikombo-Deguenon F, Belcastro A. Sex/gender phenotypes and the diagnosis and treatment of autism spectrum disorder: implications for applied behavior analysts. Behav Anal Pract. (2020) 13:263-69. doi: 10.1007/s40617-019-00376-z

8. Nielsen S, Anckarsäter H, Gillberg C, Gillberg C, Råstam M, Wentz E. Effects of autism spectrum disorders on outcome in teenage-onset anorexia nervosa evaluated by the Morgan-Russell outcome assessment schedule: a controlled community-based study. Mol Autism. (2015) 6:14. doi: 10.1186/s13229-015-0013-4

9. Tchanturia K, Adamson J, Leppanen J, Westwood H. Characteristics of autism spectrum disorder in anorexia nervosa: a naturalistic study in an inpatient treatment program. Autism. (2019) 23:123-30. doi: 10.1177/1362361317722431

10. Tchanturia K, Giombini L, Leppanen J, Kinnaird E. Evidence for cognitive remediation therapy in young people with anorexia nervosa: systematic review and meta-analysis of the literature. Eur Eat Disord Rev. (2017) 25:227-36. doi: 10.1002/erv.2522

11. Leppanen J, Sedgewick F, Treasure J, Tchanturia K. Differences in the theory of mind profiles of patients with anorexia nervosa and individuals on the autism spectrum: a meta-analytic review. Neurosci Biobehav Rev. (2018) 90:146-63. doi: 10.1016/j.neubiorev.2018.04.009

12. Tchanturia K, Davies H, Harrison A, Fox JRE, Treasure J, Schmidt U. Altered social hedonic processing in eating disorders. Int J Eat Disord. (2012) 45:962-9. doi: 10.1002/eat.22032

13. Lang K, Lopez C, Stahl D, Tchanturia K, Treasure J. Central coherence in eating disorders: an updated systematic review and meta-analysis. World J Biol Psychiatry. (2014) 15:586-98. doi: 10.3109/15622975.2014.909606

14. Tchanturia K, Davies H, Roberts M, Harrison A, Nakazato M, Schmidt $\mathrm{U}$, et al. Poor cognitive flexibility in eating disorders: examining the evidence using the wisconsin card sorting task. PLoS ONE. (2012) 7:28331. doi: 10.1371/journal.pone.0028331

15. Tchanturia K, Harrison A, Davies H, Roberts M, Oldershaw A, Nakazato M, et al. Cognitive flexibility and clinical severity in eating disorders. PLoS ONE. (2011) 6:20462. doi: 10.1371/journal.pone.0020462 article. All authors contributed to the article and approved the submitted version.

\section{FUNDING}

This study was part of Slovenian Research Agency (ARRS) Project (P3-00036 and J3-9434) and received financial support from the University Psychiatric Clinic Ljubljana and General Hospital Slovenj Gradec.

16. Westwood H, Eisler I, Mandy W, Leppanen J, Treasure J, Tchanturia K. Using the autism-spectrum quotient to measure autistic traits in anorexia nervosa: a systematic review and meta-analysis. J Autism Dev Disord. (2016) 46:964-77. doi: 10.1007/s10803-015-2641-0

17. Lindvall Dahlgren $\mathrm{C}, \mathrm{R} \emptyset \mathrm{O}$. A systematic review of cognitive remediation therapy for anorexia nervosa-development, current state and implications for future research and clinical practice. J Eat Disord. (2014) 2:26. doi: 10.1186/s40337-014-0026-y

18. Dandil Y, Smith K, Kinnaird E, Toloza C, Tchanturia K. Cognitive remediation interventions in autism spectrum condition: a systematic review. Front Psychiatry. (2020) 11:722. doi: 10.3389/fpsyt.2020.00722

19. Tchanturia K, Lock J. Cognitive remediation therapy for eating disorders: development, refinement and future directions. In: Adan RAH, Kaye WH, editors. Behavioral Neurobiology of Eating Disorders, Berlin: Springer (2010). p. 269-87.

20. Timko CA, Goulazian TJ, Fitzpatrick KK, Rodriguez D. Cognitive remediation therapy (CRT) as a pretreatment intervention for adolescents with anorexia nervosa during medical hospitalization: a pilot randomized controlled trial protocol. Pilot Feasibility Stud. (2018) 4:87. doi: 10.1186/s40814-018-0277-5

21. Tchanturia K, Smith K, Glennon D, Burhouse A. Towards an improved understanding of the anorexia nervosa and autism spectrum comorbidity: PEACE pathway implementation. Front Psychiatry. (2020) 11:640. doi: $10.3389 /$ fpsyt.2020.00640

22. Brede J, Babb C, Jones C, Elliott M, Zanker C, Tchanturia K, et al. "For me, the anorexia is just a symptom, and the cause is the autism": investigating restrictive eating disorders in autistic women. J Autism Dev Disord. (2020) 50:4280-96. doi: 10.1007/s10803-020-04479-3

23. Kinnaird E, Norton C, Stewart C, Tchanturia K. Same behaviours, different reasons: what do patients with co-occurring anorexia and autism want from treatment? Int Rev Psychiatry. (2019) 31:308-17. doi: 10.1080/09540261.2018.1531831

24. Allison C, Auyeung B, Baron-Cohen S. Toward brief "red flags" for autism screening: the short autism spectrum quotient and the short quantitative checklist in 1,000 cases and 3,000 controls. J Am Acad Child Adolesc Psychiatry. (2012) 51:202-12. doi: 10.1016/j.jaac.2011.11.003

25. Hus V, Lord C. The autism diagnostic observation schedule, module 4: revised algorithm and standardized severity scores. J Autism Dev Disord. (2014) 44:1996-2012. doi: 10.1007/s10803-014-2080-3

26. Sedgewick F, Kerr-Gaffney J, Leppanen J, Tchanturia K. Anorexia nervosa, autism, and the ADOS: how appropriate is the new algorithm in identifying cases? Front Psychiatry. (2019) 10:507. doi: 10.3389/fpsyt.2019. 00507

27. Dandil Y, Smith K, Adamson J, Tchanturia K. Individual cognitive remediation therapy benefits for patients with anorexia nervosa and high autistic features. Eur Eat Disord Rev. (2019) 28: 87-91. doi: 10.1002/erv.2707

28. Sparrow KA, Tchanturia K. Inpatient brief group therapy for anorexia nervosa: patient experience. Int J Group Psychother. (2016) 66:43142. doi: 10.1080/00207284.2016.1156406

29. Adamson J, Leppanen J, Murin M, Tchanturia K. Effectiveness of emotional skills training for patients with anorexia nervosa with autistic symptoms in group and individual format. Eur Eat Disord Rev. (2018) 26:36775. doi: 10.1002/erv.2594 
30. Tchanturia K, Dandil Y, Li Z, Smith K, Leslie M, Byford S. A novel approach for autism spectrum condition patients with eating disorders: analysis of treatment cost-savings. Eur Eat Disord Rev. (2020) 29:5148. doi: $10.1002 /$ erv. 2760

31. Luria AR. The Man with a Shattered World: The History of a Brain Wound. Cambridge MA: Harvard University Press (1972).

32. Kurtz MM. Cognitive remediation for schizophrenia: current status, biological correlates and predictors of response. Expert Rev Neurother. (2012) 12:813-21. doi: 10.1586/ern.12.71

33. Wykes T, Spaulding WD. Thinking about the future cognitive remediation therapy-what works and could we do better? Schizophr Bull. (2011) 37(Suppl. 2):S80-90. doi: 10.1093/schbul/sbr064

34. Bowie CR, Gupta M, Holshausen K. Cognitive remediation therapy for mood disorders: rationale, early evidence, and future directions. Can J Psychiatry. (2013) 58:319-25. doi: 10.1177/070674371305800603

35. Stevenson CS, Whitmont S, Bornholt L, Livesey D, Stevenson RJ. A cognitive remediation programme for adults with attention deficit hyperactivity disorder. Aust New Zeal J Psychiatr. (2002) 36:6106. doi: 10.1046/j.1440-1614.2002.01052.x

36. Rupp CI, Kemmler G, Kurz M, Hinterhuber H, Fleischhacker WW. Cognitive remediation therapy during treatment for alcohol dependence. $J$ Stud Alcohol Drugs. (2012) 73:625-34. doi: 10.15288/jsad.2012.73.625

37. Morimoto SS, Wexler BE, Alexopoulos GS. Neuroplasticity-based computerized cognitive remediation for geriatric depression. Int J Geriatr Psychiatry. (2012) 27:1239-47. doi: 10.1002/gps.3776

38. Buhlmann U, Deckersbach T, Engelhard I, Cook LM, Rauch $\mathrm{SL}$, Kathmann $\mathrm{N}$, et al. Cognitive retraining for organizational impairment in obsessive-compulsive disorder. Psychiatry Res. (2006) 144:109-16. doi: 10.1016/j.psychres.2005.10.012

39. Kucharska K, Kulakowska D, Starzomska M, Rybakowski F, Biernacka K. The improvement in neurocognitive functioning in anorexia nervosa adolescents throughout the integrative model of psychotherapy including cognitive remediation therapy. BMC Psychiatry. (2019) 19:15. doi: 10.1186/s12888-018-1984-4

40. Cholet J, Rousselet M, Donnio Y, Burlot M, Pere M, Lambert S, et al. Evaluation of cognitive impairment in a French sample of patients with restrictive anorexia nervosa: two distinct profiles emerged with differences in impaired functions and psychopathological symptoms. Eat Weight Disord. (2020) 26:1559-70. doi: 10.1007/s40519-020-00981-w.

41. Best JR, Miller PH. A developmental perspective on executive function. ChildDev. (2010) 81:1641-60. doi: 10.1111/j.1467-8624.2010.01499.x

42. Kerr-Gaffney J, Mason L, Jones E, Hayward H, Harrison A, Murphy $\mathrm{D}$, et al. Autistic traits mediate reductions in social attention in adults with anorexia nervosa. J Autism Dev Disord. (2021) 51:2077-2090 (In Press). doi: 10.1007/s10803-020-04686-y

43. Happé FGE, Booth RDL. The power of the positive: revisiting weak coherence in autism spectrum disorders. Q J Exp Psychol. (2008) 61:5063. doi: 10.1080/17470210701508731

44. Jolliffe T, Baron-Cohen S. Are people with autism and Asperger syndrome faster than normal on the embedded figures test? J Child Psychol Psychiatry. (1997) 38:527-34. doi: 10.1111/j.1469-7610.1997.tb01539.x

45. Westwood H, Stahl D, Mandy W, Tchanturia K. The set-shifting profiles of anorexia nervosa and autism spectrum disorder using the Wisconsin card sorting test: a systematic review and meta-analysis. Psychol Med. (2016) 46:1809-27. doi: 10.1017/S0033291716000581

46. Leppanen J, Adamson J, Tchanturia K. Impact of cognitive remediation therapy on neurocognitive processing in anorexia nervosa. Front Psychiatry. (2018) 9:96. doi: 10.3389/fpsyt.2018.00096

47. Sproch LE, Anderson KP, Sherman MF, Crawford SF, Brandt HA. A randomized controlled trial of group cognitive remediation therapy for anorexia nervosa: effects on set-shifting tasks for inpatient adults and adolescents. Int J Eat Disord. (2019) 52:1004-14. doi: 10.1002/eat.23143

48. Okuda T, Asano K, Numata N, Hirano Y, Yamamoto T, Tanaka M, et al. Feasibility of cognitive remediation therapy for adults with autism spectrum disorders: a single-group pilot study. Neuropsychiatr Dis Treat. (2017) 13:2185-91. doi: 10.2147/NDT.S141555

49. De Vries M, Prins PJM, Schmand BA, Geurts HM. Working memory and $\mathrm{f}$ cognitive flexibility-training for children with an autism spectrum disorder: a randomized controlled trial. J Child Psychol Psychiatry Allied Disciplines. (2015) 56:566-76. doi: 10.1111/jcpp.12324

50. Bölte S, Feineis-Matthews S, Leber S, Dierks T, Hubl D, Poustka F. The development and evaluation of a computer-based program to test and to teach the recognition of facial affect. Int J Circ Health. (2002) 61:618. doi: 10.3402/ijch.v61i0.17503

51. Eack SM, Hogarty SS, Greenwald DP, Litschge MY, Porton SA, Mazefsky CA, et al. Cognitive enhancement therapy for adult autism spectrum disorder: results of an 18-month randomized clinical trial. Autism Res. (2018) 11:51930. doi: 10.1002/aur.1913

52. Miyajima M, Omiya H, Yamashita K, Miyata T, Yambe K, Matsui M, et al. The effects of cognitive remediation therapy using the frontal/executive program for autism spectrum disorder. Int J Psychiatry Med. (2016) 51:22335. doi: $10.1177 / 0091217416651254$

53. Golan O, Baron-Cohen S. Systemizing empathy: teaching adults with Asperger syndrome or high-functioning autism to recognize complex emotions using interactive multimedia. Dev Psychopathol. (2006) 18:591617. doi: $10.1017 /$ S0954579406060305

54. Turner-Brown LM, Perry TD, Dichter GS, Bodfish JW, Penn DL. Brief report: feasibility of social cognition and interaction training for adults with high functioning autism. J Autism Dev Disord. (2008) 38:177784. doi: 10.1007/s10803-008-0545-y

55. Hajri $M$, Abbès $Z$, Yahia HB, Ouanes $S$, Halayem S, Bouden A, et al. Effects of cognitive remediation therapy in children with autism spectrum disorder: study protocol. Int J Sci Res. (2016) 5:2007-12. doi: 10.21275/v5i7.ART201648

56. Tchanturia K, Larsson E, Adamson J. How anorexia nervosa patients with high and low autistic traits respond to group cognitive remediation therapy. BMC Psychiatry. (2016) 16:334. doi: 10.1186/s12888-016-1044-x

57. Hajri M, Abbes Z, Ben YH, Boudali M, Hamza M, Bouden A, et al. Place of cognitive remedition therapy in the management of autism spectrum disorder. Int J Psychos Rehabil. (2017) 21:55-6. doi: 10.37200/ ijpr

58. Eack SM, Greenwald DP, Hogarty SS, Bahorik AL, Litschge MY, Mazefsky $\mathrm{CA}$, et al. Cognitive enhancement therapy for adults with autism spectrum disorder: results of an 18-month feasibility study. J Autism Dev Disord. (2013) 43:2866-77. doi: 10.1007/s10803-013-1834-7

59. Dandil Y, Baillie C, Tchanturia K. Cognitive remediation therapy as a feasible treatment for a young person with anorexia nervosa and autism spectrum disorder comorbidity: a case study. Clin Case Stud. (2020) 19:11532. doi: $10.1177 / 1534650119890425$

60. de Marchena AB, Eigsti IM, Yerys BE. Brief report: generalization weaknesses in verbally fluent children and adolescents with autism spectrum disorder. J Autism Dev Disord. (2015) 45:3370-6. doi: 10.1007/s10803-0152478-6

61. Dingemans AE, Danner UN, Donker JM, Aardoom JJ, van Meer F, Tobias $\mathrm{K}$, et al. The effectiveness of cognitive remediation therapy in patients with a severe or enduring eating disorder: a randomized controlled trial. Psychother Psychosom. (2014) 83:29-36. doi: 10.1159/000355240

62. Brockmeyer T, Ingenerf $\mathrm{K}$, Walther S, Wild B, Hartmann M, Herzog W, et al. Training cognitive flexibility in patients with anorexia nervosa: a pilot randomized controlled trial of cognitive remediation therapy. Int $J$ Eat Disord. (2013) 47:24-31. doi: 10.1002/eat.22206

63. Lock J, Agras WS, Fitzpatrick KK, Bryson SW, Jo B, Tchanturia K. Is outpatient cognitive remediation therapy feasible to use in randomized clinical trials for anorexia nervosa? Int J Eat Disord. (2013) 46:56775. doi: $10.1002 /$ eat.22134

64. Steinglass JE, Albano AM, Simpson HB, Wang Y, Zou J, Attia E, et al. Confronting fear using exposure and response prevention for anorexia nervosa: a randomized controlled pilot study. Int J Eat Disord. (2013) 47:174-80. doi: 10.1002/eat.22214

65. Pitt S, Lewis R, Morgan S, Woodward D. Cognitive remediation therapy in an outpatient setting: a case series. Eat Weight Disord. (2010) 15:2816. doi: $10.1007 / \mathrm{BF} 03325310$

66. Pretorius N, Dimmer M, Power E, Eisler I, Simic M, Tchanturia K. Evaluation of a cognitive remediation therapy group for adolescents with anorexia nervosa: pilot study. Eur Eat Disord Rev. (2012) 20:3215. doi: $10.1002 /$ erv. 2176 
67. Dahlgren CL, Lask B, Landrø NI, Rø Ø. Neuropsychological functioning in adolescents with anorexia nervosa before and after cognitive remediation therapy: a feasibility trial. Int J Eat Disord. (2013) 46:576-81. doi: 10.1002/eat.22155

68. Dahlgren CL, Lask B, Landrø NI, Rø Ø. Developing and evaluating cognitive remediation therapy (CRT) for adolescents with anorexia nervosa: a feasibility study. Clin Child Psychol Psychiatry. (2014) 19:47687. doi: $10.1177 / 1359104513489980$

69. Easter A, Tchanturia K. Therapists' experiences of cognitive remediation therapy for anorexia nervosa: implications for working with adolescents. Clin Child Psychol Psychiatry. (2011) 16:233-46. doi: 10.1177/13591045114 01185

70. Lask B, Roberts A. Family cognitive remediation therapy for anorexia nervosa. Clin Child Psychol Psychiatr. (2015) 20:207-17. [Epub ahead of print]. doi: 10.1177/1359104513504313

71. Whitney J, Easter A, Tchanturia K. Service users' feedback on cognitive training in the treatment of anorexia nervosa: a qualitative study. Int J Eat Disord. (2008) 41:542-50. doi: 10.1002/eat.20536

72. Wood L, Al-Khairulla H, Lask B. Group cognitive remediation therapy for adolescents with anorexia nervosa. Clin Child Psychol Psychiatry. (2011) 16:225-31. doi: 10.1177/1359104511404750

73. Zuchova S, Erler T, Papezova H. Group cognitive remediation therapy for adult anorexia nervosa inpatients: First experiences. Eat Weight Disord. (2013) 18:269-273. doi: 10.1007/s40519-013-0041-Z

74. Abbate-Daga G, Buzzichelli S, Marzola E, Amianto F, Fassino S. Effectiveness of cognitive remediation therapy (CRT) in anorexia nervosa: a case series. J Clin Exp Neuropsychol. (2012) 34:1009-15. doi: 10.1080/13803395.2012.704900

75. Dahlgren CL, Lask B, Landro NI, Rø $\varnothing$. Patient and parental self-reports of executive functioning in a sample of young female adolescents with anorexia nervosa before and after cognitive remediation therapy. Eur Eat Disord Rev. (2014) 22:45-52. doi: 10.1002/erv.2265

76. Tchanturia K, Davies H, Lopez C, Schmidt U, Treasure J, Wykes T. Neuropsychological task performance before and after cognitive remediation in anorexia nervosa: a pilot case-series. Psychol Med. (2008) 38:13713. doi: 10.1017/S0033291708003796

77. Genders R, Tchanturia K. Cognitive remediation therapy (CRT) for anorexia in group format: a pilot study. Eat Weight Disord. (2010) 15:e2349. doi: 10.1007/BF03325304

78. Tchanturia K, Davies H, Campbell IC. Cognitive remediation therapy for patients with anorexia nervosa: preliminary findings. Ann Gen Psychiatr. (2007) 6:1-16. doi: 10.1186/1744-859X-6-14

79. Davies H, Tchanturia K. Cognitive remediation therapy as an intervention for acute anorexia nervosa: a case report. Eur Eat Disord Rev. (2005) 13:3116. doi: 10.1002/erv.655

80. Pretorius N, Tchanturia K. Anorexia nervosa: how people think and how we address it in cognitive remediation therapy. Therapy. (2007) 4:42332. doi: 10.2217/14750708.4.4.423

81. Tchanturia K, Whitney J, Treasure J. Can cognitive exercises help treat anorexia nervosa? Eat Weight Disord. (2006) 11:e1126. doi: 10.1007/BF03327574

82. Tchanturia K. Cognitive Remediation Therapy (CRT) for Eating and Weight Disorders. 1st ed. New York, NY: Routledge (2015).

83. Lang K, Lloyd S, Khondoker M, Simic M, Treasure J, Tchanturia K. Do children and adolescents with anorexia nervosa display an inefficient cognitive processing style? PLoS ONE. (2015) 10:e0131724. doi: 10.1371/journal.pone.0131724

84. Lang $\mathrm{K}$, Treasure J, Tchanturia K. Is inefficient cognitive processing in anorexia nervosa a familial trait? A neuropsychological pilot study of mothers of offspring with a diagnosis of anorexia nervosa. World J Biol Psychiatry. (2016) 17:258-65. doi: 10.3109/15622975.2015. 1112035

85. van Noort BM, Kraus MKA, Pfeiffer E, Lehmkuhl U, Kappel V. Neuropsychological and behavioural shortterm effects of cognitive remediation therapy in adolescent anorexia nervosa: a pilot study. Eur Eat Disord Rev. (2016) 24:69-74. doi: 10.1002/erv.2383

86. Harrison A, Stavri P, Ormond L, McEnemy F, Akyol D, Qureshi A, et al. Cognitive remediation therapy for adolescent inpatients with severe and complex anorexia nervosa: a treatment trial. Eur Eat Disord Rev. (2018) 26:230-40. doi: 10.1002/erv.2584

87. Giombini L, Moynihan J, Turco M, Nesbitt S. Evaluation of individual cognitive remediation therapy (CRT) for the treatment of young people with anorexia nervosa. Eat Weight Disord. (2016). 22:667-73. doi: 10.1007/s40519-016-0322-4

88. van Noort BM, Pfeiffer E, Lehmkuhl U, Kappel V. Cognitive remediation therapy for children with anorexia nervosa. $Z$ Kinder Jugendpsychiatr Psychother. (2015) 43:351-5. doi: 10.1024/1422-4917/ a000372

89. Giombini L, Nesbitt S, Waples L, Finazzi E, Easter A, Tchanturia T. Young people's experience of individual cognitive remediation therapy (CRT) in an inpatient eating disorder service: a qualitative study. Eat Weight Disord. (2017) 23:499-505. doi: 10.1007/s40519-017-0369-x

90. Lang K, Roberts M, Lopez C, Goddard E, Khondoker M, Treasure J, et al. An investigation of central coherence in eating disorders: a synthesis of studies using the Rey-Osterrieth Complex Figure Test. PLoS ONE. (2016) 11:e0165467. doi: 10.1371/journal.pone.0165467

91. Tchanturia K, Lounes N, Holttum S. Cognitive remediation in anorexia nervosa and related conditions: a systematic review. Eur Eat Disord Rev. (2014) 22:454-62. doi: 10.1002/erv.2326

92. Carr A, Tchanturia K, Dufour E, Cowan M, Himmerich H. Evidence-Based and Novel Psychological Therapies for People with Anorexia Nervosa. London: IntechOpen (2020).

93. Giombini L, Nesbitt S, Cox H, Foxall A, Sharia T, Easter A, et al. Cognitive remediation therapy (CRT) in a specialist inpatient eating disorder service for children and adolescents: CAN-CRT study protocol for a pilot randomised controlled trial. Eur Eat Disord Rev. (2018) 26:43846. doi: 10.1002/erv.2592

94. Olff M, Frijling JL, Kubzansky LD, Bradley B, Ellenbogen MA, Cardoso $\mathrm{C}$, et al. The role of oxytocin in social bonding, stress regulation and mental health: an update on the moderating effects of context and interindividual differences. Psychoneuroendocrinology. (2013) 38:188394. doi: 10.1016/j.psyneuen.2013.06.019

95. Geng Y, Zhao W, Zhou F, Ma X, Yao S, Hurlemann R, et al. Oxytocin enhancement of emotional empathy: generalization across cultures and effects on amygdala activity. Front Neurosci. (2018) 12:512. doi: 10.3389/fnins.2018.00512

96. Lancaster K, Goldbeck L, Pournajafi-Nazarloo H, Connelly JJ, Carter CS, Morris JP. The role of endogenous oxytocin in anxiolysis: structural and functional correlates. Biol Psychiatry Cogn Neurosci Neuroimaging. (2018) 3:618-25. doi: 10.1016/j.bpsc.2017.10.003

97. Loyens E, De Bundel D, Demaegdt H, Chai SY, Vanderheyden P, Michotte $\mathrm{Y}$, et al. Antidepressant-like effects of oxytocin in mice are dependent on the presence of insulin-regulated aminopeptidase. Int J Neuropsychopharmacol. (2013) 16:1153-63. doi: 10.1017/S1461145712001149

98. Tops M, Huffmeijer R, Linting M, Grewen K, Light K, Koole S, et al. The role of oxytocin in familiarization-habituation responses to social novelty. Front Psychol. (2013) 4:761. doi: 10.3389/fpsyg.2013.00761

99. Heinrichs M, Baumgartner T, Kirschbaum C, Ehlert U. Social support and oxytocin interact to suppress cortisol and subjective responses to psychosocial stress. Biol Psychiatry. (2003) 54:138998. doi: 10.1016/S0006-3223(03)00465-7

100. Freeman SM, Palumbo MC, Lawrence RH, Smith AL, Goodman MM, Bales KL. Effect of age and autism spectrum disorder on oxytocin receptor density in the human basal forebrain and midbrain. Transl Psychiatry. (2018) 8:257. doi: 10.1038/s41398-018-0315-3

101. Leslie M, Silva P, Paloyelis Y, Blevins J, Treasure J. A systematic review and quantitative meta-analysis of oxytocin's effects on feeding. J Neuroendocrinol. (2018) 30:e12584. doi: 10.1111/jne.12584

102. Frank GKW. Pharmacotherapeutic strategies for the treatment of anorexia nervosa-too much for one drug? Expert Opin Pharmacother. (2020) 21:1045-58. doi: 10.1080/14656566.2020.1748600

103. Tyszkiewicz-Nwafor M, Rybakowski F, Dmitrzak-Weglarz M, Skibinska M, Paszynska E, Dutkiewicz A, et al. Brain-derived neurotrophic factor and oxytocin signaling in association with clinical symptoms in adolescent inpatients with anorexia nervosa-a longitudinal study. Front Psychiatry. (2020) 10:1032. doi: 10.3389/fpsyt.2019.01032 
104. Rutigliano G, Rocchetti M, Paloyelis Y, Gilleen J, Sardella A, Cappucciati $M$, et al. Peripheral oxytocin and vasopressin: biomarkers of psychiatric disorders? A comprehensive systematic review and preliminary meta-analysis. Psychiatry Res. (2016) 241:207-20. doi: 10.1016/j.psychres.2016.04.117

105. Schmelkin C, Plessow F, Thomas JJ, Gray EK, Marengi DA, Pulumo R, et al. Low oxytocin levels are related to alexithymia in anorexia nervosa. Int $J$ Eat Disord. (2017) 50:1332-8. doi: 10.1002/eat.22784

106. Lawson EA, Holsen LM, Santin M, Meenaghan E, Eddy KT, Becker AE, et al. Oxytocin secretion is associated with severity of disordered eating psychopathology and insular cortex hypoactivation in anorexia nervosa. $J$ Clin Endocrinol Metab. (2012) 97:E1898-908. doi: 10.1210/jc.2012-1702

107. Valdespino A, Antezana L, Ghane M, Richey JA. Alexithymia as a transdiagnostic precursor to empathy abnormalities: the functional role of the insula. Front Psychol. (2017) 8:2234. doi: 10.3389/fpsyg.2017. 02234

108. Vuillier L, Carter Z, Teixeira AR, Moseley RL. Alexithymia may explain the relationship between autistic traits and eating disorder psychopathology. Mol Autism. (2020) 11:63. doi: 10.1186/s13229-020-00364-z

109. Kim YR, Kim CH, Cardi V, Eom JS, Seong Y, Treasure J. Intranasal oxytocin attenuates attentional bias for eating and fat shape stimuli in patients with anorexia nervosa. Psychoneuroendocrinology. (2014) 44:13342. doi: 10.1016/j.psyneuen.2014.02.019

110. Hasselbalch KC, Lanng KR, Birkeland M, Sjögren M. Potential shortcomings in current studies on the effect of intranasal oxytocin in Anorexia Nervosa and healthy controls-A systematic review and meta-analysis. Psychopharmacology (Berl). (2020) 237:2891-903. doi: 10.1007/s00213-020-05626-5

111. Kim YR, Eom JS, Yang JW, Kang J, Treasure J. The impact of oxytocin on food intake and emotion recognition in patients with eating disorders: a double blind single dose within-subject cross-over design. PLOS ONE. (2015) 10:e0137514. doi: 10.1371/journal.pone.0137514

112. Leppanen J, Cardi V, Ng KW, Paloyelis Y, Stein D, Tchanturia K, et al. The effects of intranasal oxytocin on smoothie intake, cortisol and attentional bias in anorexia nervosa. Psychoneuroendocrinology. (2017) 79:167-74. doi: 10.1016/j.psyneuen.2017.01.017

113. Russell J, Maguire S, Hunt GE, Kesby A, Suraev A, Stuart J, et al. Intranasal oxytocin in the treatment of anorexia nervosa: randomized controlled trial during re-feeding. Psychoneuroendocrinology. (2018) 87:8392. doi: 10.1016/j.psyneuen.2017.10.014

114. Acevedo SF, Valencia C, Lutter M, McAdams CJ. Severity of eating disorder symptoms related to oxytocin receptor polymorphisms in anorexia nervosa. Psychiatry Res. (2015) 228:641-8. doi: 10.1016/j.psychres.2015. 05.040

115. Sala M, Han K, Acevedo S, Krawczyk DC, McAdams CJ. Oxytocin receptor polymorphism decreases midline neural activations to social stimuli in anorexia nervosa. Front Psychol. (2018) 9:2183. doi: 10.3389/fpsyg.2018.02183

116. Meziane H, Schaller F, Bauer S, Villard C, Matarazzo V, Riet F, et al. An early postnatal oxytocin treatment prevents social and learning deficits in adult mice deficient for magel2, a gene involved in Prader-Willi syndrome and autism. Biol Psychiatry. (2015) 78:85-94. doi: 10.1016/j.biopsych.2014. 11.010

117. Modahl C, Green L, Fein D, Morris M, Waterhouse L, Feinstein C, et al. Plasma oxytocin levels in autistic children. Biol Psychiatry. (1998) 43:2707. doi: $10.1016 / \mathrm{S} 0006-3223(97) 00439-3$

118. Parker KJ, Garner JP, Libove RA, Hyde SA, Hornbeak KB, Carson DS, et al. Plasma oxytocin concentrations and OXTR polymorphisms predict social impairments in children with and without autism spectrum disorder. Proc Natl Acad Sci USA. (2014) 111:12258-63. doi: 10.1073/pnas.1402236111

119. Green L, Fein D, Modahl C, Feinstein C, Waterhouse L, Morris M. Oxytocin and autistic disorder: alterations in peptide forms.
Biol Psychiatry. (2001) 50:609-13. doi: 10.1016/S0006-3223(01) 01139-8

120. Puglia MH, Connelly JJ, Morris JP. Epigenetic regulation of the oxytocin receptor is associated with neural response during selective social attention. Transl Psychiatry. (2018) 8:116. doi: 10.1038/s41398-018-0159-x

121. Siu MT, Goodman SJ, Yellan I, Butcher DT, Jangjoo M, Grafodatskaya D, et al. DNA methylation of the oxytocin receptor across neurodevelopmental disorders. J Autism Dev Disord. (2021). doi: 10.1007/s10803-020-04792-x. [Epub ahead of print].

122. Guastella AJ, Einfeld SL, Gray KM, Rinehart NJ, Tonge BJ, Lambert $\mathrm{TJ}$, et al. Intranasal oxytocin improves emotion recognition for youth with autism spectrum disorders. Biol Psychiatry. (2010) 67:692-4. doi: 10.1016/j.biopsych.2009.09.020

123. Guastella AJ, Gray KM, Rinehart NJ, Alvares GA, Tonge BJ, Hickie IB, et al. The effects of a course of intranasal oxytocin on social behaviors in youth diagnosed with autism spectrum disorders: a randomized controlled trial. $J$ Child Psychol Psychiatry. (2015) 56:444-52. doi: 10.1111/jcpp.12305

124. Kosaka $\mathrm{H}$, Munesue T, Ishitobi M, Asano M, Omori M, Sato M, et al. Longterm oxytocin administration improves social behaviors in a girl with autistic disorder. BMC Psychiatry. (2012) 12:110. doi: 10.1186/1471-244X-12-110

125. Tachibana M, Kagitani-Shimono K, Mohri I, Yamamoto T, Sanefuji W, Nakamura A, et al. Long-term administration of intranasal oxytocin is a safe and promising therapy for early adolescent boys with autism spectrum disorders. J Child Adolesc Psychopharmacol. (2013) 23:1237. doi: $10.1089 /$ cap. 2012.0048

126. Gordon I, Vander Wyk BC, Bennett RH, Cordeaux C, Lucas MV, Eilbott JA, et al. Oxytocin enhances brain function in children with autism. Proc Natl Acad Sci USA. (2013) 110:20953-8. doi: 10.1073/pnas.1312857110

127. Gordon I, Jack A, Pretzsch CM, Vander Wyk B, Leckman JF, Feldman R, et al. Intranasal oxytocin enhances connectivity in the neural circuitry supporting social motivation and social perception in children with autism. Sci Rep. (2016) 6:35054. doi: 10.1038/srep35054

128. Greene RK, Spanos M, Alderman C, Walsh E, Bizzell J, Mosner MG, et al. The effects of intranasal oxytocin on reward circuitry responses in children with autism spectrum disorder. J Neurodev Disord. (2018) 10:12. doi: 10.1186/s11689-018-9228-y

129. Baker E, Stavropoulos KKM. The effects of oxytocin administration on individuals with ASD: neuroimaging and behavioral evidence. Prog Mol Biol Transl Sci. (2020) 173:209-38. doi: 10.1016/bs.pmbts.2020.04.009

130. Verhees MWFT, Houben J, Ceulemans E, Bakermans-Kranenburg MJ, van IJzendoorn MH, Bosmans G. No side-effects of single intranasal oxytocin administration in middle childhood. Psychopharmacology (Berl). (2018) 235:2471-7. doi: 10.1007/s00213-018-4945-1

Conflict of Interest: The authors declare that the research was conducted in the absence of any commercial or financial relationships that could be construed as a potential conflict of interest.

Publisher's Note: All claims expressed in this article are solely those of the authors and do not necessarily represent those of their affiliated organizations, or those of the publisher, the editors and the reviewers. Any product that may be evaluated in this article, or claim that may be made by its manufacturer, is not guaranteed or endorsed by the publisher.

Copyright $\odot 2021$ Plemeniti Tololeski, Suhodolčan Grabner and Kumperscak. This is an open-access article distributed under the terms of the Creative Commons Attribution License (CC BY). The use, distribution or reproduction in other forums is permitted, provided the original author(s) and the copyright owner(s) are credited and that the original publication in this journal is cited, in accordance with accepted academic practice. No use, distribution or reproduction is permitted which does not comply with these terms. 